\title{
Revisión de los estudios comparativos entre regeneración tisular guiada y cirugía mucogingival en el tratamiento de recesiones gingivales
}

\author{
BASCONES MARTÍNEZ, A.* \\ IBERO SAGASTIBELZA, I** \\ CASTRO LARA, J.** \\ LAZARO CALVO, P.***
}

\begin{abstract}
Bascones Martínez, A; Ibero Sagastibelza, I; Castro Lara, G; Lázaro Calvo, P; Revisión de los estudios comparativos entre regeneración tisular guiada y cirugía mucogingival en el tratamiento de recesiones gingivales, 2000; 12: 1-17
\end{abstract}

\begin{abstract}
RESUMEN
Las recesiones vestibulares son una de las patologías de más frecuente consulta al especialista en Periodoncia. Acarrean una clínica - debido a la exposición radicular - que pueden requerir su tratamiento, tanto desde el punto de vista funcional como estético.

A lo largo de la historia de la cirugía mucogingival se han desarrollado diferentes técnicas quirúrgicas, y actualmente se piensa que las más predecibles para el tratamiento de recesiones anchas y profundas son el injerto libre de tejido conectivo y los procedimientos de regeneración tisular guiada.
\end{abstract}

Este artículo tiene como objetivo repasar los estudios comparativos entre dichas técnicas para concluir cual de ellas obtiene mejores resultados.

\section{PALABRAS CLAVE}

Recesión gingival; cobertura radicular; injerto de tejido conectivo; regeneración tisular guiada; cirugía mucogingival.

\section{INTRODUCCIÓN}

El conjunto de tejidos blandos que rodean al diente y al hueso alveolar es decir, encía insertada, encía libre y mucosa alveolar constituyen el denominado complejo mucogingival. Dicha unidad puede presentar dos tipos de defectos: unos cerrados que se denominan bolsas periodontales y otros abiertos que reciben el nombre de recesiones gingivales (RG). Tanto unos como otros suponen una pérdida de inserción.

La cirugía mucogingival (CMG) ha centrado principalmente su interés en el tratamiento de las recesio- nes gingivales, las cuales se pueden definir "como aquellas lesiones en las que el margen gingival migra apicalmente y pasa a localizarse por debajo de la unión amelocementaria, dejando una porción de cemento radicular expuesta al medio oral"'(1). Las consecuencias de la exposición de la superficie radicular denudada son problemas de hipersensibilidad, caries y erosiones radiculares y un efecto antiestético en los dientes anteriores.

En los numerosos estudios realizados para conocer la frecuencia con la que aparecen las RG en las exploraciones bucales, se ha observado que se trata de una

Catedrático de Medicina Bucal y Periodoncia. Director Master Periodoncia, Universidad Complutense de Madrid

Odontólogo. Alumno doctorado U.C.M.

** Master en Periodoncia de la U.C.M. 


\section{AVANCES}

Volumen 12 - No 1 - Mayo 2000

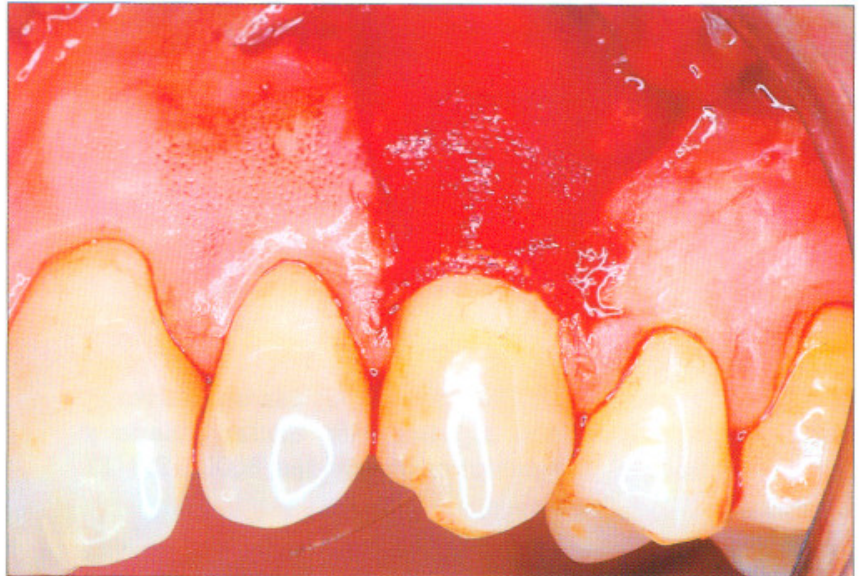

Fig. 1: Incisión

patología periodontal con una elevada incidencia (2).Bouchard (1994)(3) calcula que en los países industrializados un $75 \%$ de los individuos con edades de 30 y 31 años presentan RG en las superficies vestibulares. Fombellida y cols. (1989)(4) observaron en un estudio realizado en España con 176 pacientes con edades comprendidas entre los 15 y 69 años que el $70 \%$ de la muestra padecían RG.

La etiopatogenia de la RG no está aún totalmente aclarada aunque se considera que es multifactorial. Dichos factores se dividen en determinantes (inflamación por mala higiene, cepillado traumático, trauma oclusal, movimientos ortodóncicos y procedimientos yatrogénicos) y en predisponentes o substrato anatómico predisponente (calidad de las encías, cortical ósea fina e inserción alta de los frenillos)(2)(5)(6). En los estudios epidemiológicos se observa que la acción continua de los primeros, sobre una condición morfológico-anatómica de los tejidos periodontales susceptible, aumenta la frecuente aparición de la retracción marginal(1).

El tratamiento de las RG está justificado cuando el paciente se queja de padecer alguna de las consecuencias de la exposición de la raíz al medio oral anteriormente citadas. Por otro lado, a veces, la encía marginal está continuamente inflamada, aunque el paciente esté motivado sobre la importancia de la higiene oral. En estos casos puede existir dificultad para realizar una correcta remoción de la placa a ese nivel ya sea por la morfología de la RG (estrechas y profundas), por un fondo de vestíbulo poco profundo, o porque la mucosa alveolar presenta sensibilidad al cepillarse lo que hace que el paciente evite ese área.

Para recubrir las superficies radiculares expuestas tenemos distintas técnicas quirúrgicas (Ver tabla I). Unas consisten en la toma del tejido donante de áreas adyacentes apicales o laterales al defecto (colgajos) o

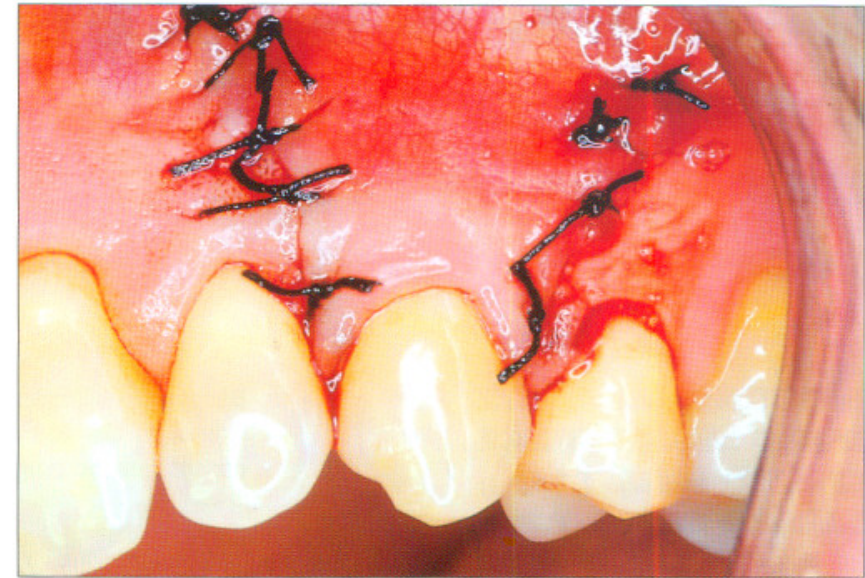

Fig. 2: Sutura

a distancia (injertos) y que podríamos denominar como técnicas reparativas (cirugía mucogingival clásica (CMG)) y otras más recientes en las que se regenera el tejido que recubrirá la raíz denudada mediante técnicas de membrana de barrera y que son los procedimientos de regeneración tisular guiada (RTG).

La mayoría de los procedimientos quirúrgicos de recubrimiento radicular han demostrado ser predecibles y dar un buen resultado estético. En este sentido, de todos ellos, el trasplante de tejido conectivo de mucosa palatina y los procedimientos de RTG son los mejores.

En este trabajo se realiza una revisión de los estudios experimentales comparativos existentes en la bibliografía entre CMG y los procedimientos de RTG con el objetivo de concluir cual de las dos técnicas proporciona mejores resultados en cuanto a recubrimiento radicular, resultados estéticos e incremento de la encía queratinizada.

\section{CIRUGÍA MUCOGINGIVAL}

Es quizá la CMG la parte de la cirugía periodontal que más controversia ha sufrido a lo largo de la historia, en cuanto a objetivos terapéuticos, indicaciones y técnicas quirúrgicas. A continuación vamos únicamente a realizar un resumen de la extensa bibliografía sobre este tema y destacaremos ciertos aspectos.

El origen de la cirugía mucogingival viene ya desde finales del siglo anterior y principios de este. Raetzke (1984)(7) recoge en su estudio como Schnitzler y Ewalt en 1894 publicaron la colocación con éxito de injerto de piel en lesiones orales tras la eliminación de epiteliomas. En 1902, Younger y Harlan describieron por primera vez el injerto gingival procedente de encía retromolar para cubrir una raíz expuesta. 


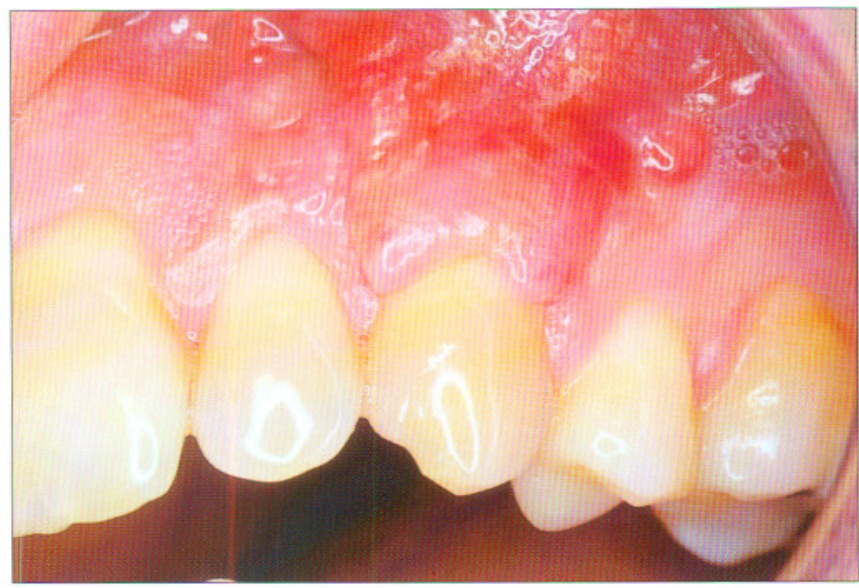

Fig. 3: Postoperatorio un mes.

Una de las primeras técnicas mucogingivales que aparecieron fueron las vestibuloplastias. El único objetivo que tenían era incrementar la encía insertada. El dolor y las molestias postoperatorias que originaban estos procedimientos, los resultados tan decepcionantes en el incremento de la encía queratinizada, así como la aparición de estudios que demostraban que la encía insertada no jugaba ningún papel en la enfermedad periodontal y que una banda mínima de encía insertada pueden garantizar la salud periodontal, hicieron que estas técnicas pasaran a la historia (8)(9).

En 1956 Grupe y Warren (10) describieron la técnica del colgajo reposicionado lateralmente que consistía, de una manera básica, en la realización de un colgajo de espesor total en la zona mesial o distal a la RG para posteriormente desplazarlo hacia la raíz denudada y fijarlo mediante suturas. Estos autores incluían el periostio en el colgajo para mejorar la fijación tejido conectivo-cemento. Sin embargo tiene el inconveniente de dejar el hueso del área donante expuesto sin el recubrimiento perióstico, lo que puede suponer una severa reabsorción ósea de la cresta así como un dolor postoperatorio que desaconsejan esta técnica.

Para evitar dichas complicaciones postoperatorias se publicaron diferentes modificaciones en la técnica original como los colgajos laterales de espesor parcial, los colgajos de espesor combinado, la estimulación periostica o la combinación con injertos gingivales libres, de los cuales no vamos a entrar en detalle (10-17)

También aparecieron técnicas más conservadoras en las que se obtenía uno o dos colgajos rotados pediculados a partir de las papilas adyacentes al defecto. Se trata de los colgajos oblicuos-rotados(18), colgajo transposicionado (21) o los colgajos de doble papila (20) respectivamente.

Las indicaciones de esta técnica son el recubrimiento de recesiones únicas (anchas-superficiales o estrechas-profundas), con un área adyacente a la superficie a recubrir que presente una encía queratinizada de grosor y anchura adecuada (sin recesiones) y una cortical ósea gruesa (para evitar el riesgo de dehiscencias y fenestraciones), un vestíbulo profundo (pues de lo contrario se puede originar una tensión en la base del colgajo que comprometería su vascularización) y que no existan frenillos que causen tensión en el colgajo al desplazarlo. El aspecto estético que se obtiene es adecuado.

Los resultados obtenidos con los colgajos rotados en el recubrimiento radicular no son tan buenos como las técnicas posteriores aunque para aquellos años eran aceptables (Ver tabla II). Hoy en día, en la literatura, los colgajos rotados apenas se utilizan en los distintos estudios de cirugía mucogingival.

Un segundo grupo de colgajos pediculados son aquellos en los que el tejido donante se toma apical al defecto y luego se reposiciona coronalmente para recubrirlo. Inicialmente fueron descritos por Norberg (21) aunque la técnica actual fue describita por Allen y Miller (1989)(22). Resumidamente, esta consistía en realizar una incisión horizontal apical a la papila unidas mediante otra incisión intrasulcular. A continuación se realiza dos incisiones verticales oblicuas de descarga para levantar un colgajo trapezoidal de espesor parcial y con un deslizamiento coronal se sutura.

Allen y Miller describieron esta técnica en el recubrimiento radicular de $\mathrm{RG}$ únicas de tipo I pequeñas o moderadas. Los resultados obtenidos por ellos y otros autores (aunque son escasos) fueron bastantes buenos (Ver tabla II). El aspecto estético conseguido es también bueno. Esta técnica está limitada y hay que ser muy selectivos por la necesidad de una encía queratinizada de $3 \mathrm{~mm}$. como mínimo acompañando al defecto mucogingival, un fondo de vestíbulo profundo y sin inserciones musculares aberrantes. Con estos procedimientos no se va a poder incrementar el ancho de encía insertada.

La principal crítica que recibieron estos estudios del colgajo de reposición coronal fue que en las recesiones grandes con una banda de encía queratinizada estrecha no era más fácil obtener resultados tan buenos. Sin embargo, Harris y Harris (23) obtuvieron un recubrimiento completo en 6 de los 18 defectos, los cuales tenían $2 \mathrm{~mm}$ o menos de encía queratinizada. Además existe un trabajo con esta técnica realizado por Blanc y cols. (24) quienes obtuvieron un porcentaje promedio de recubrimiento radicular del $66 \%$ en recesiones con una media de profundidad de $5.2 \mathrm{~mm}$. y una encía queratinizada de $1.7 \mathrm{~mm}$. de anchura. Estos mismos autores concluyen que la altura de la encía queratinizada inicial no afecta el resultado de la 
recesión y que se puede realizar un colgajo de reposición coronal en presencia de una encía queratinizada de poca altura $(<3 \mathrm{~mm})$.

En un intento de solucionar la falta de encía queratinizada en determinados casos en los que se va a realizar un colgajo coronal, Bernimoullin y cols. (1975)(25) describieron una técnica en la que colocaban en un primer momento, en el defecto, un injerto gingival libre para aumentar la encía insertada y, dos meses después en un segundo acto quirúrgico, levantaban un colgajo que posicionaban coronalmente para terminar de recubrir la recesión gingival.

Durante los años 70 esta técnica de doble acto quirúrgico de Bernimoullin fue el método más predecible (27), a raíz de ulteriores trabajos como los de Maynard (1977)(26), Caffesse y Guinard (1978)(51), Matter (1979)(61),



Fig. 4: Recisión gingival de clase I Teenenbaum y cols. (1980)(63) y Liu y Solt (1980)(62) en los cuales se obtuvo un recubrimiento comprendido entre el $59 \%$ y el $75 \%$.

Sin embargo a partir de los excelentes resultados y de las mejores ventajas que ofrecen otras técnicas (injertos gingivales libres, injertos de tejidos conectivos y RTG), esta técnica hoy en día a quedado en desuso.

Una variante del colgajo de reposición coronal es el colgajo bipediculado semilunar de Tarnow (1986)(28). Es un procedimiento sencillo, conservador del cual no se han reflejado resultados en la literatura y que puede permitir recubrir pequeñas recesiones.

Como resumen podemos concluir que los colgajos coronales sin actos quirúrgicos previos, resulta un buen tratamiento en recesiones de clase I con una banda de encía queratinizada apical al defecto más o menos adecuada.

Cuando necesitamos un tejido donante con mejores condiciones que el que nos proporciona el área donante adyacente, es necesario tomarlo a distancia (generalmente de la mucosa palatina), obteniéndose así los injerto autógenos de tejido blando. Estos procedimientos suponen una segunda herida quirúrgica al paciente y un aumento de las molestias postoperatorias.

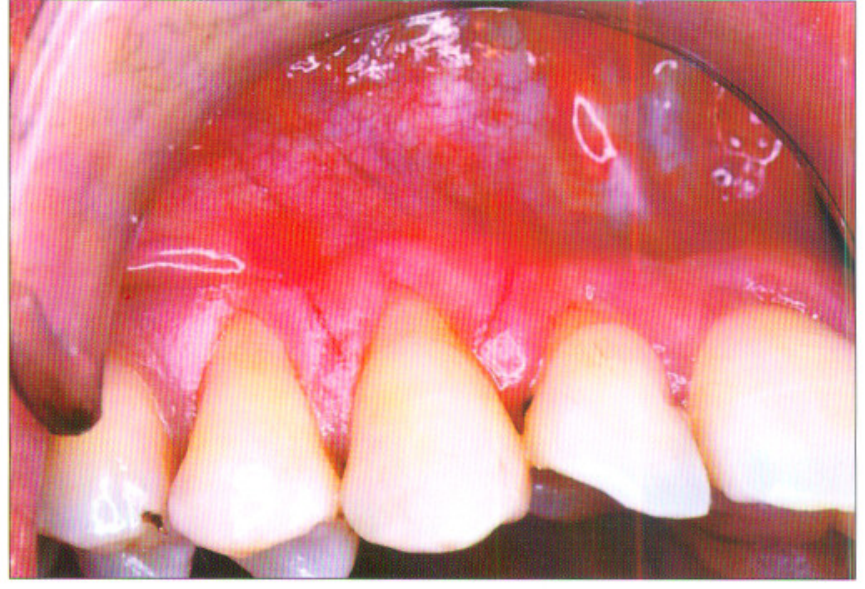

Fig. 5: Diseño del colgajo trapezoidal

A diferencia de los colgajos, el tejido injertado carece de base o pedículo que le proporcione una vascularización intrínseca y por lo tanto corre un mayor riesgo de necrosis.

Los injertos pueden ser de ser de epitelio queratinizado y tejido conectivo (injertos gingivales libres) o solo de tejido conectivo. Comenzaremos describiendo los primeros.

Younger y Harlan describieron en 1904 por primera vez el injerto gingival libre utilizando con éxito la encía retromolar para cubrir una raíz expuesta.

No obstante, el recubrimiento radicular utilizando autoinjertos libres recibió muy poca atención, hasta la década de los 60, en los que Björn (1963)(29) publicó las primeras imágenes de esta técnica.

Su empleo se difundió de forma importante y aparecieron autores como Nabers (1966), Hawley y Staffileno (1969), Sullivan y Atkins (1968) (30)(31). Fue éste trabajo el que marcó la pauta más importante en el desarrollo del injerto gingival libre en esta época pues publicaron el fundamento clásico de la técnica, sus principios biológicos y los procesos de cicatrización. Ward (1974), Livingston (1975), Mlinek y col. (1973) (64) y Guinard y Caffesse (1977)(1) quienes publican casos clínicos y observaciones adicionales a estos procedimientos. Aunque algunas áreas tratadas proporcionan esperanzas, el consenso en aquel tiempo fue que las áreas con recesiones gingivales estrechas y poco profundas o estrechas y profundas, presentaban los resultados más predecibles mientras que los dientes con recesiones gingivales anchas y profundas tenían un potencial limitado para el recubrimiento mediante un injerto gingival libre, indicándose únicamente para conseguir un aumento de la banda de encía insertada y prevenir la progresión de la recesión gingival. 


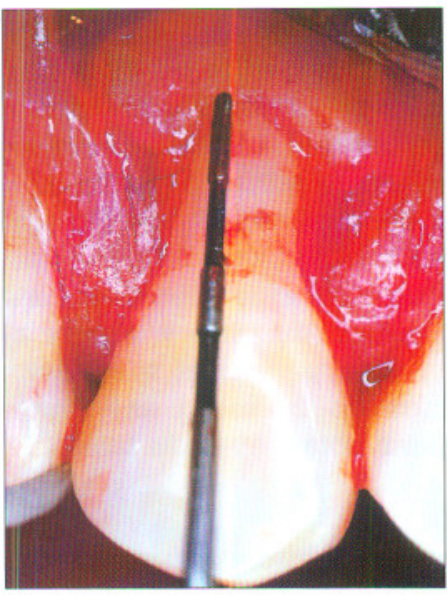

Fig. 6: Profundidad del defecto

El problema que presentan los injertos para su nutrición e hidratación es la falta de vascularización intríniseca. Para ello, los vasos sanguíneos del tejido conectivo deben anastomarse con aquellos procedentes de los tejidos del lecho receptor (periostio, ligamento periodontal, encía adyacente).

La superficie radicular expuesta es un área avascular que no va a contribuir a la revascularización del tejido conectivo que se sitúa sobre ella, lo que supone un riesgo de necrosis. El establecimiento de la circulación sanguínea a ese nivel procederá de la vascularización de los márgenes mesial, distal y apical. Cuanto más ancha y profunda sea la recesión (clases II) más dificil va a ser tratarla pues más comprometida va a estar la revascularización del tejido a nivel del área radicular.

Como hemos comentado anteriormente, en los años 60 y 70, en los cuales solo existían los injertos epitelio-conectivos, se consideraban que tenían un potencial de éxito en el recubrimiento de las recesiones de clase II muy limitado. Autores como Sullivan y Atkins (1968) (30)(31) afirmaron que "este tipo de recesiones son demasiado anchas para que dos puntos colaterales circulatorios abarquen la parte del injerto sobre el área avascular coronal. Además la circulación apical está demasiado lejos para ayudar al mantenimiento del injerto sobre el área avascular coronal. Todo ello originará el necrosamiento del tejido. Los tres puntos de circulación colateral desde los márgenes vasculares mesial y distal mantendrán 1-2 $\mathrm{mm}$ del nuevo tejido queratinizado sobre la porción apical de la recesión ancha y profunda".

A partir de esto, y aunque existían casos en los que se habían obtenido recubrimentos completos (Mlinek, 1973)(64), el injerto gingival libre quedó confinado al aumento de la encía insertada y a lo sumo al tratamiento de recesiones mínimas. Durante este periodo se realizaba un segundo procedimiento quirúrgico para posicionar coronalmente la encía (Bernimoullin, 1975)(24).

Sin embargo, en los años 80 Miller (1985)(32)(33)(34), Holbrook y Ochsenbein (1983) (35), Corn y Marks (1983) (36) e Ibbot y cols. (37) (en sus estudios con injertos gingivales libres en recesiones anchas y pro- fundas (Clase II), obtiene porcentajes de superficie radicular recubierta y porcentajes de dientes con recubrimientos completos muy elevados (ver tabla III), demostrando que esta técnica presenta una alta predecibilidad de éxito, que no es necesario un segundo procedimiento y que la anchura y la profundidad de la RG no parecen que son consideraciones a la hora de pretender recubrir una raíz como hasta entonces se había creído.

El motivo de la mejoría en los resultados con injertos libres epitelio-conectivos se debe a una técnica quirúrgica en la cual se tienen en cuenta ciertos principios biológicos encaminados fundamentalmente para favorecer la revascularización del tejido injertado. Así por ejemplo estos autores abogaron por la utilización de injertos de tamaños prediseñados y gruesos, con un espesor de $1.5 \mathrm{~mm}$ como mínimo para incluir todo el tejido conectivo en el injerto y así mantener intacto todo el sistema capilar favoreciendo la revascularización. Incluso ciertos autores aconsejaron incluir también parte de la submucosa (tejido adiposo y glandular) dentro del injerto para mejorar los resultados.

Otra consideración importante que se introdujo fue la preparación de las raíces expuestas. En un primer paso se aplanan las raices mediante curetas o fresas de diamante para eliminar el cálculo, la placa bacteriana y el cemento afecto. Además se reduce la dimensión mesio-distal de la superficie avascular. En un segundo paso se acondicio-

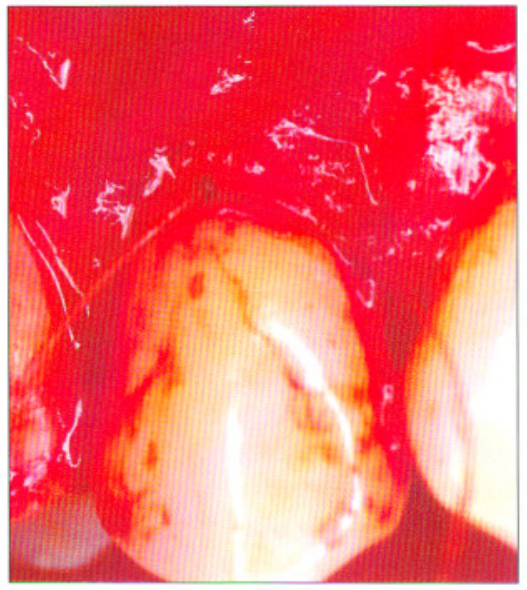

Fig. 7.: Colocación de la membrana nan con sustancias del tipo del ácido cítrico o HCE de tetraciclinas. Respecto a la utilidad de estas sustancias existen desacuerdos pues en los estudios comparativos no se ha demostrado que en los casos en los que se aplica se obtenga mejores resultados que en aquellos otros en los que no (38)(39).

Otra consideración que posiblemente hizo mejorar los resultados fue la mejora en la técnica de sutura del injerto (35). El objetivo consistía en estirar el injerto para contrarrestar su contracción y adaptarlo lo mejor posible a la anatomía del lecho receptor mediante suturas tensas estratégicamente distribuidas. 
Los resultados buenos obtenidos por estos autores crean una controversia, aún existente, sobre el potencial del injerto gingival libre para cubrir predeciblemente superficies radiculares. Hoy en día, existe el criterio unánime en la comunidad científica de considerar el injerto gingival libre como una técnica de alta predictibilidad para aumentar el ancho de la banda de encía adherida, existiendo divisón de opiniones en cuanto a la conveniencia de usarlo en el tratamiento de la recesión gingival anchas y profundas.

Las ventajas de esta técnica son que no existen limitaciones para obtener tejido donante a partir del área adyacente ni riesgo de dehiscencias a ese nivel (a diferencia de los colgajos pediculados) y que permite profundizar el vestíbulo.

Por el contrario, presentan las desventajas de proporcionar un aspecto antiestético (color blanco queloide que contraindica su uso en zonas con compromiso estético), requiere una segunda herida quirúrgica en el paladar que incrementa las molestias postoperatorias y a veces causa un rechazo en el paciente (a veces la mucosa palatina es muy fina y no permite obtener un adecuado injerto). Además no presenta vascularización intrínseca con lo cual existe un mayor riesgo de necrosis en el área avascular dificultando el recubrimiento radicular de recesiones anchas y profundas. Esta técnica requiere una sutura más o menos compleja y se han descrito casos de aparición de exóstosis tras su aplicación (40)(41).

Las indicaciones son aquellos casos en los que se pretende aumentar la encía insertada de manera importante y predecible; así como en aquellos en los que se pretende recubrir superficies radiculares expuestas únicas o múltiples. A pesar de que se han obtenido buenos resultados en el recubrimiento radicular de recesiones anchas y profundas, aún sigue existiendo controversia sobre este punto aunque si se quiere conseguir una alta seguridad se debería de usar sólo en recesiones estrechas y profundas como puede ser en los dientes antero-inferiores que presentan las raíces más estrechas.

Posterior a todas estas técnicas surgió otra, el autoinjerto de tejido conectivo palatino recubierto por un colgajo pediculado. Este procedimiento fue descrito por primera vez para el recubrimiento radicular por Langer y Langer (42) en 1986 (aunque fue introducido previamente vez por el autor español Pérez Fernández (43)). Los autores levantaban un colgajo trapezoidal de espesor parcial en el lecho receptor seguido o no de la preparación y acondicionamiento radicular según criterio del profesional. A continuación se realiza una incisión horizontal en el paladar a 5 ○ $6 \mathrm{~mm}$. del margen gingival y su posterior disección apical, luego otra incisión 1.5 a $2 \mathrm{~mm}$. coronal a la primera obteniéndose así el injerto de tejido conectivo con dicho grosor y una banda de epitelio. Posteriormente se transplanta el tejido al lecho receptor donde es suturado coronal a la linea amelocementaria para, por último, ser recubierto por el colgajo reposicionado lo más coronalmente posible sin crear tensión en la base del mismo que comprometa su vascularización. Hay autores (3) que prefieren eliminar la banda de epitelio queratinizado y recubrir completamente el injerto para mejorar el resultado estético y evitar la aparición de bolsas a ese nivel (salvo que se desee aumentar notablemente la encía insertada).

En la literatura se han descrito distintas variantes de esta técnica como el recubrimiento del injerto con un colgajo de doble papila de espesor total (44) o parcial (45) (46) o los procedimientos "sobres" introducidos por primera ver por Pérez Fernández que consisten en despegar, moviendo alrededor del defecto una cureta u objeto romo, un colgajo de espesor parcial creando así una especie de "sobre" o "bolsillo" en el cual se introduce el tejido conectivo. Esta técnica se diferencia de la de Langer y Langer en que es más conservadora pues no se necesita realizar incisiones de liberación. Posteriormente esta técnica ha sido modificada como, por ejemplo, el "injerto de tejido blando mediante sobre supraperiostico" descrito por Allen (47) para tratar recesiones múltiples y continuas. Sin embargo, tiene el inconveniente de que es difícil introducir y fijar el tejido donante adecuadamente en el lecho receptor y de ser un procedimiento técnicamente más exigente pues hay que evitar lesionar las papilas.

Otro procedimiento es el descrito por Tinti y Parma (48) en el cual, el tejido donante se obtenía de las papilas adyacentes al defecto para evitar realizar una segunda herida quirúrgica en el paladar.

En cuanto a los resultados en el recubrimiento radicular y ganancia de inserción obtenidos con el injerto de tejido conectivo son excelentes en el tratamiento de recesiones gingivales anchas y profundas (Ver tabla III). Es la técnica, hoy por hoy, que mejores resultados y más predecibles proporciona (según los datos de la bibliografía cabría esperar un recubrimiento del $90 \%$ ).

Así mismo, el incremento de la anchura de la encía queratinizada que se obtiene es importante pues dicho tejido conectivo procedente de una mucosa queratinizada palatina induce genéticamente la queratinización de la mucosa alveolar (49)(50).

Las ventajas de este procedimiento son: proporciona un buen resultado estético gracias al colgajo pediculado que lo recubre lo que lo indica en recesiones 
únicas o múltiples con compromiso estético. Mejor postoperatorio que en el injerto gingival libre pues la herida quirúrgica palatina es menor. El riesgo de necrosis del tejido donante sobre la superficie avascular es menor que en el injerto gingival libre pues recibe un doble aporte vascular, por un lado procedente del lecho receptor y por otro lado del colgajo pediculado que lo recubre. Esto explicaría porque esta técnica presenta una mejor predecibilidad en el tratamiento de recesiones anchas y profundas, a diferencias de otros procedimientos.

Sin embargo, tiene las desventajas de que se siguen realizando dos heridas quirúrgicas al paciente y en aquellos casos en los que el paciente no acepte que se le manipule el paladar o presente uno fino o pobre en tejido conectivo, será necesario recurrir a otros procedimientos. Además en el caso de recesiones en los dientes del sector antero-inferior se complica la técnica debido a la dificultad de reposicionar un colgajo coronalmente debido a las importantes inserciones musculares a ese nivel.

\section{REGENERACIÓN TISULAR GUIADĀ (RTG)}

La regeneración tisular guiada basa su eficacia en el concepto mismo de regeneración que conlleva, que es el restablecimiento de un nuevo ligamento periodontal, cemento y hueso en un área de raíz previamente denudada por la enfermedad periodontal; y que la Academia Americana de Periodoncia define como "la reproducción o reconstrucción de una parte perdida o lesionada para restaurar la arquitectura y función del periodonto". Es el procedimiento ideal. En el caso del periodonto, el nuevo epitelio gingival, el tejido conectivo subyacente y el ligamento periodontal se forman a partir de estos mismos tejidos, mientras que el hueso y el cemento se originan a partir de células indiferenciadas del conectivo (su tejido precursor) que se transformarán en osteoblastos y cementoblastos (72). Este proceso supera al de reparación, que es el que ocurre de manera fisiológica en el organismo, y que consiste en la cicatrización de una herida por tejido (diferente del autóctono y generalmente de carácter fibroconectivo) que no restaura completamente la arquitectura o función de las partes.

Estos procesos extrapolados al tejido gingival nos introducen dos nuevos conceptos, como son la nueva inserción (new attachment) y la adherencia epitelial larga (long junctional ephitelium). Entendemos por nueva inserción a la unión del tejido conectivo o epitelio con la superficie radicular la cual había sido privada de su complejo de inserción original. Puede ser por adhesión epitelial y/o adaptación conectiva 0 inserción; implicando por tanto un proceso de rege-

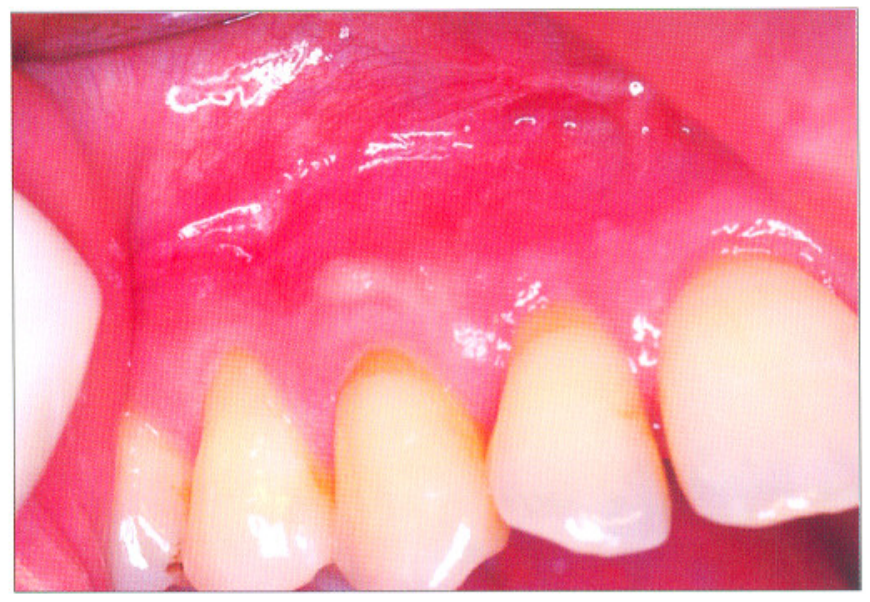

Fig. 9: Aspecto al mes

neración. Por otro lado tenemos la adherencia epitelial larga, que es la migración del epitelio gingival hacia apical, repoblando la superficie radicular, tras enfermedad o cirugía periodontal. Es, por tanto, un proceso de reparación y como tal no es el ideal, aunque es la forma más frecuente de reparación con técnicas quirúrgicas no regenerativas (resectivas), motivado porque el epitelio gingival crece a mayor velocidad en sentido apical que el hueso y el ligamento lo hacen en sentido coronal (73).

Estas características la hacen ideal para el tratamiento de recesiones gingivales asociadas a dehiscencias óseas, pero que - según afirman varios autores deben de tener un mínimo de pérdida de inserción de $5 \mathrm{~mm}$ en la exploración clínica, pues en el caso contrario no se obtendrían los resultados esperados e incluso se obtendrían resultados negativos por lo que se debería usar una técnica convencional(74)(75)(76)(77)(78)(79). En este tipo de terapia también debemos tener en cuenta el tener toda la encía insertada que nos sea posible, pues ayuda a la manejabilidad del colgajo y a la cobertura de la membrana.

En lo que se refiere a la técnica quirúrgica empleada en la regeneración tisular guiada para el tratamiento de recesiones gingivales, no existen grandes diferencias respecto a este procedimiento aplicado a otro tipo de patologías o situaciones (furcaciones, implantología, etc.), si bien es interesante realizar algunas matizaciones en lo que al diseño del colgajo y a la colocación de la membrana se refiere.

De esta manera, para estas situaciones, Tinti (80) propone el llamado colgajo trapezoidal, que consiste en realizar una incisión horizontal en la parte más apical de la exposición radicular, seguido de dos incisiones liberadoras oblicuas que le dan nombre a la técnica. 


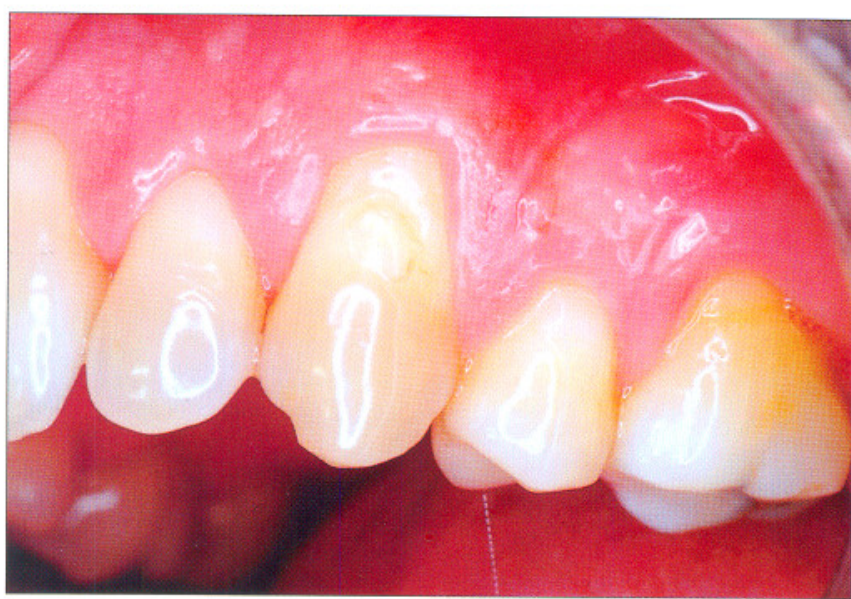

Fig. 10.: Recesión gingival a nivel del 23.

Tres milímetros por encima de la primera incisión se realiza otro colgajo de espesor parcial en el que incluimos el epitelio de las papilas remanentes, de manera que podemos colocar sin tensión el colgajo en posición coronal y cubrir así todo el defecto más fácilmente y asegurando una buena vascularización con una base ancha mayor que las obtenidas con la técnica estándar.

En cuanto a la colocación de la membrana, es fácil entender que un aspecto crítico en este tipo de defectos es la obtención del denominado "efecto tienda”, que cree un espacio entre la superficie radicular y la cara interna de la membrana que pueda ser ocupado por el coágulo sanguíneo y permita la posterior regeneración de los tejidos. Para ello podemos realizar una superficie cóncava en la raíz dentaria con ayuda de los instrumentos rotatorios o impregnar la membrana de barrera con sustancias que le confieran rigidez a la misma; pero la más comúnmente utilizada es la curvación de la membrana previa a su colocación con la ayuda de hilo de sutura. Posteriormente -y tenidas en cuenta estas consideraciones- se completa la técnica de manera convencional.

Fue McCall (77)el primer autor que habló del concepto de nueva inserción en 1926, tras la realización de un curetaje; pero no fue hasta mucho más tarde-en 1976- cuando Melcher (81) y Nyman (82) postularon una serie de conceptos básicos, en los que afirmaba que la reparación periodontal depende de la estirpe que lo realiza, y que la ideal era el ligamento periodontal, que migrando coronalmente sería capaz de formar nueva inserción debido a que son capaces de producir cemento y fibras colágenas.

Posteriormente Nyman y cols. (1982) (83)realizaron el primer estudio donde se utilizaron membranas como barrera para permitir la migración de las células del

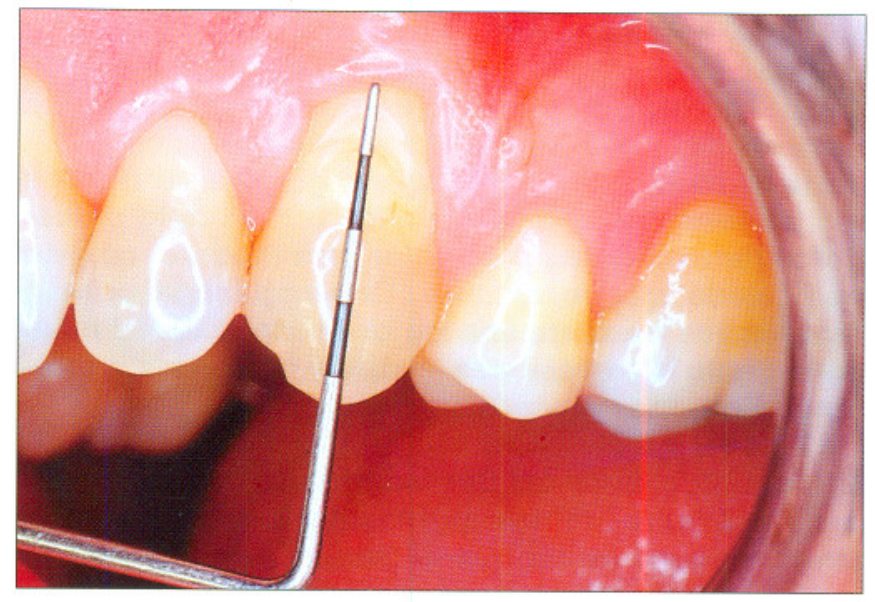

Fig. 11: Profundidad clínica del defecto.

ligamento periodontal y dificultar la migración del resto de las estirpes celulares. Lo realizó en monos y para ello utilizó un filtro Millipore que colocó entre el colgajo de tejido blando y la superficie radicular tratada para que el epitelio y el tejido conectivo gingival pudieran desviarse de la superficie radicular. Si bien. la técnica no consiguió apartar las células derivadas de hueso, se consideró que las células del ligamento periodontal podrían colonizar más rápidamente la superficie radicular para permitir la obtención del resultado deseado. Se observó la formación de cemento, fibras colágenas y regeneración ósea, demostrándose que puede formarse cemento e inserción de tejido conectivo nuevo en superficies radiculares privadas quirúrgicamente del cemento y ligamento periodontal originales.

En ese mismo año el citado autor (84) realizó el primer experimento con humanos, en un varón de 47 años, utilizando igualmente un filtro Millipore y demostrando histológicamente una ganancia de 7 $\mathrm{mm}$ de nueva inserción de tejido conectivo en sentido coronal y hueso rellenando el defecto vertical.

Cuatro años después, Gottlow (85) experimentó con seres humanos y le dio el nombre de regeneración tisular guiada, con el que se conoce esta técnica actualmente. Esta vez utilizaron membranas de politetrafluoroetileno expandido (e-PTFE) en diez pacientes. Los resultados variaron considerablemente de un paciente a otro, mostrando que factores como el grado de recesión de la cicatrización, la morfología del defecto periodontal y la cantidad de periodonto remanente son factores que pudieran influir en el proceso de regeneración. Aunque casi siempre hubo formación de nuevo cemento con fibras insertadas, la regeneración ósea fue restringida a áreas donde había defectos angulares, pues en este caso (al igual que en los defectos de furcación) el ligamento periodontal que proporcionaba 


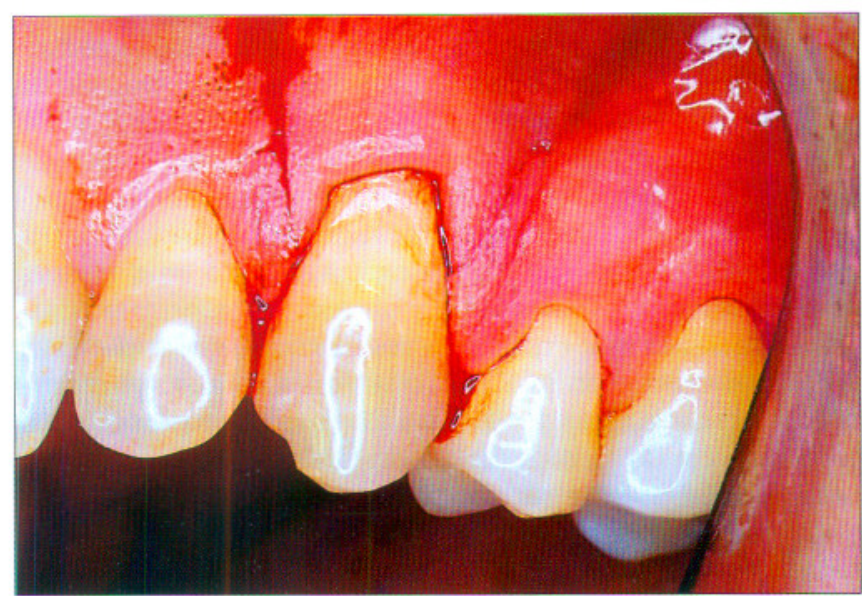

Fig. 12: Realización de las incisiones

las células progenitoras estaban en los bordes laterales del defecto y no sólo en la parte apical como ocurre en los defectos horizontales. Este hallazgo mostró que el tejido conectivo de inserción puede formarse sin la concomitante aparición de hueso alveolar y que el crecimiento del tejido óseo y la regeneración del ligamento no son fenómenos relacionados. Además, al igual que ocurría en estudios anteriores, concluyeron que la velocidad de migración de las células del ligamento periodontal es mayor que la de las células óseas; pues en ningún caso se produjo anquilosis.

En 1990, Buser y cols. (86) aplicaron el principio de la regeneración tisular guiada en la colocación de implantes tanto para aumento de la cresta ósea por hueso insuficiente como para evitar la reabsorción del hueso postextracción; y acuñaron el término de regeneración ósea guiada, en vez de la osteopromoción descrita por Dahlin (77) tres años antes.

Por último, en el año 1991,Cortellini y col. (87) evaluaron la posibilidad de obtener tejido conectivo para tratar recesiones gingivales. Los análisis histo-

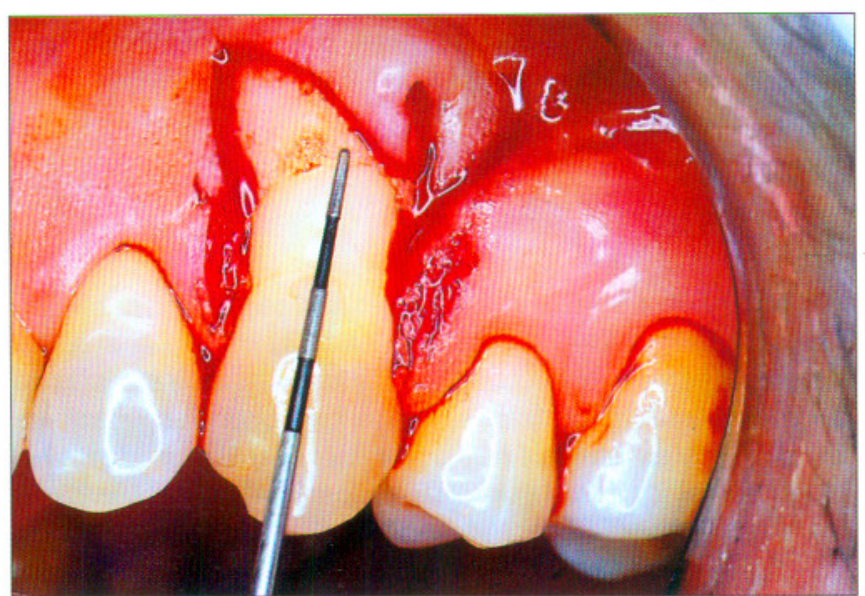

Fig. 13.: Levantamiento del colgajo

métricos demostraron una apreciable regeneración de nuevo tejido de inserción conectivo, siendo actualmente uno de los campos de mayor investigación y ensayo en lo que a técnicas regenerativas se refiere.

Así, son múltiples los ensayos clínicos realizados para el tratamiento de recesiones gingivales mediante regeneración tisular guiada, tanto con el uso de membranas reabsorbibles, como no reabsorbibles. Desde que en el año 1992 Pini Prato (88) realizase el primer estudio en humanos, múltiples autores han obtenido resultados favorables en el empleo de esta técnica (ver tabla V), en parámetros biológicos tales como la ganancia de inserción, disminución de la recesión e incremento de encía queratinizada, sólo equiparables con los obtenidos por el injerto de tejido conectivo.

Como se puede observar existen diferencias importantes entre unos estudios y otros ya que los resultados de este procedimiento es muy lábil a la técnica, al operador, al material empleado, al tamaño de la muestra (en el caso de ciertos estudios (88) (96) (101) (102) se obtienen resultados muy positivos,

Tabla I. Clasificación de las técnicas de Cirugía Mucogingival.

\begin{tabular}{|c|c|c|}
\hline A) Colgajos: & $\begin{array}{l}\text { a.1: laterales al defecto: } \\
\text { a.2: apicales al defecto: }\end{array}$ & $\begin{array}{l}\text { - Reposicionado lateralmente. } \\
\text { - Oblicuo rotado. } \\
\text { - Transposicionado. } \\
\text { - Doble papila. } \\
\text { - Reposicionado coronalmente. } \\
\text { - Colgajo semilunar }\end{array}$ \\
\hline B) Injertos autólogos: & & $\begin{array}{l}\text { - gingival libre o epitelio-conectivo. } \\
\text { - conectivo (Técnica bilaminar). }\end{array}$ \\
\hline C) Regeneración tisular guiada: & & $\begin{array}{l}\text { - Membranas no reabsorbibles:e-PTFE } \\
\text { - Membranas reabsorbibles. }\end{array}$ \\
\hline
\end{tabular}


pero sólo en $1 \circ 2$ individuos) y otros factores que hacen difícil la homogeneidad de los resultados.

\section{DISCUSIÓN}

En todos los estudios mencionados anteriormente hemos comprobado que tanto la RTG como la cirugía mucogingival son técnicas válidas para el tratamiento de recesiones gingivales, ahora bien, se nos plantean las siguientes cuestiones: ¿es alguna de las dos técnicas superior a la otra?, ¿tiene cada técnica sus indicaciones específicas?.

A este respecto, se han realizado numerosos estudios comparativos de ambas técnicas y así, en 1992 Pini
Prato y cols. (89) comparan los resultados de la técnica de doble paso (injerto gingival libre y posterior colgajo de reposición coronal según la técnica de Harvey) y la RTG con membranas no reabsorbibles de e-PTFE (con técnica del colgajo trapezoidal, curvatura de las membranas y prescripción de antibióticos y enjuagues con clorhexidina). A los seis meses se evaluaron los resultados y se encontraron parámetros similares en cuanto a recubrimiento radicular, siendo mejores en la RTG (que tenía una mayor profundidad de bolsas y pérdida de inserción) en cuanto a reducción de profundidad de bolsas y ganancia de inserción; y mejor en el grupo de la cirugía mucogingival en cuanto a aumento de encía queratinizada. Además se observó que en el grupo de la RTG existía correlación entre la reducción del defecto y la profundidad inicial de la lesión, cosa que no ocurría con

Tabla II. Resultados con colgajos pediculados de tejidos blandos.

\begin{tabular}{|c|c|c|c|}
\hline Autor & Técnica & $\begin{array}{l}\% \text { recubrimiento } \\
\text { radicular }\end{array}$ & $\begin{array}{l}\% \text { dientes } \\
\text { recubr. total }\end{array}$ \\
\hline Smucler (1976)(12) & CPL & 72 & \\
\hline Guinard y Caffesse (1978)(51) & CPL & 69 & - \\
\hline Guinard y Caffesse (1980) (52) & CPL & 82 & - \\
\hline Espinel y Caffese (1981) (53) & CPL & 74 & - \\
\hline Oles (1985)(54) & CPL & 71 & - \\
\hline Caffese y col. (1987) & CPL & 56 & - \\
\hline Allen y Miller (1989)(22) & CRC (Tipo I) & 98 & 86 \\
\hline Harris y Harris(23) & CRC (Tipo I) & 98.8 & 95 \\
\hline Blanc y cols. (1991) (24) & CRC & 66 & - \\
\hline Borghetti y Gardella (1990) & CRC (Tipo I) & 88.5 & 60 \\
\hline $\begin{array}{l}\text { Wennström y } \\
\text { Zucchelli (1996) (56) }\end{array}$ & CRC & 97 & 80 \\
\hline Zade y col. (1985) (65) & $\begin{array}{l}\text { CPL } \\
\text { CDP }\end{array}$ & $\begin{array}{l}41 \\
69\end{array}$ & - \\
\hline Oles y col. (1988) (66) & CPL & 75 & 45 \\
\hline Kunjanma y col. (1986) (67) & $\begin{array}{l}\mathrm{CPL} \\
\mathrm{CDP}\end{array}$ & $\begin{array}{l}73 \\
41\end{array}$ & - \\
\hline Romanes y col. (1993) (68) & CRC & 70 & - \\
\hline
\end{tabular}

$\mathrm{CPL}=$ Colgajo posicionado lateralmente.

$\mathrm{CRC}=$ Cogado reposicionado coronalmente.

$\mathrm{CPD}=$ Colgajo de doble papila 
Tabla III. Resultados con injertos libres epitelizados.

\begin{tabular}{|c|c|c|c|}
\hline Autor & Técnica & $\begin{array}{l}\% \text { recubrimiento } \\
\text { radicular }\end{array}$ & $\begin{array}{l}\text { \% dientes } \\
\text { recubr. total }\end{array}$ \\
\hline $\begin{array}{l}\text { Holbrook y } \\
\text { Ochsenbein (1983) (35) }\end{array}$ & IGL & $\begin{array}{l}<3 \mathrm{~mm}: 95.5 \\
3-4 \mathrm{~mm}: 80.6 \\
>5 \mathrm{~mm}: 76.6\end{array}$ & \\
\hline Miller (1985) (33) & $I G L+A \cdot C$ & $\begin{array}{l}\text { Clase I: } 100 \\
\text { Clase II: } 90\end{array}$ & $\begin{array}{c}100 \\
88\end{array}$ \\
\hline Ibbot (1985) (38) & $\begin{array}{c}I G L \\
I G L+A . C .\end{array}$ & $\begin{array}{l}55 \\
52 \\
\end{array}$ & - \\
\hline $\begin{array}{l}\text { Borghetti y } \\
\text { Gardella (1990) (55) }\end{array}$ & IGL+A.C. & $\begin{array}{l}<3 \mathrm{~mm}: 96 \\
>3 \mathrm{~mm}: 71\end{array}$ & $\begin{array}{l}64 \\
11 \\
\end{array}$ \\
\hline Tolmie y cols. (1990) (57) & $I G L+A . C$ & 87 & 73 \\
\hline $\begin{array}{l}\text { Michaelides y } \\
\text { Wilson (1995) (58) }\end{array}$ & IGL & 77 & - \\
\hline Garcia-Calderon (1997) (59) & IGL (Clases I y II) & - & 81.25 \\
\hline Matter (1980) (69) & IGL & 67 & 17 \\
\hline
\end{tabular}

$I G L=$ Injerto gingival libre

A. C. $=$ Ác. cítrico

Tabla IV. Resultados con injertos de tejido conectivo.

\begin{tabular}{|l|c|c|c|}
\hline Autor & Técnica & $\begin{array}{c}\text { \% recubrimiento } \\
\text { radicular }\end{array}$ & $\begin{array}{c}\text { \% dientes } \\
\text { recubr. total }\end{array}$ \\
\hline Raetzke (1985) (7) & ITC sobre & 80 & 41.7 \\
\hline Allen (1994) (47) & ITC sobre & 84 & 61 \\
\hline Nelson (1987) (44) & ITC+CDP & $7-10 \mathrm{mm:} \mathrm{85}$ & 50 \\
& & $4-6 \mathrm{mm:} \mathrm{92}$ & 67 \\
\hline Harris (1994) (45) & ITC+CDP & 97.7 & 89 \\
\hline Borghetti (1994) (60) & ITC+CRC & 71 & 20 \\
\hline Bouchard (1994) (3) & ITC+CRC (A.C.) & 70 & 33 \\
\hline Wennström y & ITC+CRC & 65 & 88 \\
\hline Zucchelli (1996) (56) & ITC+CRC & 98 & 80 \\
\hline Tinti y Parma (1996) (48) & CRC & 97 & - \\
\hline Levine y col. (1991) (70) & ITC papilar & 91.9 & 86 \\
\hline Harris (1992) (46) & ITC+CRC & 97 & 80 \\
\hline Jahnkeyral (1993) (71) & ITC+CRC+TC & 97 & 56 \\
\hline
\end{tabular}

ITC $=$ Injerto de tejido conectivo

$\mathrm{CRC}=$ Colgajo reposicionado coronalmente.
$\mathrm{CDP}=$ Colgajo de doble papila

$\mathrm{TC}=$ Clorhidrato de tetraciclina. 
Tabla V. Resultados con Regeneración tisular guiada.

\begin{tabular}{|c|c|c|}
\hline Autor & Técnica & $\begin{array}{c}\% \text { recubrimiento } \\
\text { radicular }\end{array}$ \\
\hline Tinti (1992) (80) & ePTFE & 55 \\
\hline Pini Prato (1992) (88) & ePTFE & 100 \\
\hline Pini Prato (1992) (89) & ePTFE & 72.7 \\
\hline Torosian (1992) (90) & ePTFE & 60 \\
\hline Cortellini (1993) (91) & ePTFE & 50 \\
\hline Tinti (1993) (92) & ePTFE (Au.) & 77.3 \\
\hline Pini Prato (1993) (93) & ePTFE & 88.6 \\
\hline Tinti (1994) (94) & ePTFE (Ti) & 73.8 \\
\hline Trombelli (1994) (95) & ePTFE+Fi & 77.4 \\
\hline Santos (1995) (96) & ePTFE & 100 \\
\hline Trombelli (1995) (97) & $\mathrm{ePTFE}+\mathrm{HCL}+\mathrm{Fi}$ & 71.7 \\
\hline Trombelli (1995) (98) & $\mathrm{ePTFE}+\mathrm{HCL}+\mathrm{Fi}$ & 77.6 \\
\hline Pini Prato (1995) (99) & Reab. & 64.8 \\
\hline Trombelli (1995) (98) & ePTFE+HCL+Fi & 77.6 \\
\hline Roccuzzo (1996) (100) & $\begin{array}{l}\text { ePTFE } \\
\text { Reab. }\end{array}$ & $\begin{array}{l}83.2 \\
82.4\end{array}$ \\
\hline Ito (1996) (101) & ePTFE & 100 \\
\hline De Sanctis (1997) (102) & Reab. & 100 \\
\hline Waterman (1997) (103) & Reab. & 76 \\
\hline Shieh (1997) (104) & Reab. & 51.55 \\
\hline Trombelli (1998) (105) & Reab. & 65 \\
\hline
\end{tabular}

ePTFE $=$ Politetrafluoretileno-expandido $\quad \mathrm{Fi}=$ Fibrin-Fibronectina $\quad \mathrm{HCL}=$ Tetraciclinas Reab. $=$ Membranas reabsorbibles .

el grupo de cirugía mucogingival.

Este mismo autor realiza un estudio de seguimiento a 4 años (106) de estos pacientes y confirma que los resultados son estables (e incluso mejoran en lo que se refiere a la profundidad de sondaje y ganancia de inserción, manteniéndose estable en lo que a recubrimiento radicular se refiere) pasado ese tiempo, si bien se confirma que en el caso de la RTG los resulta- dos más satisfactorios se obtienen en aquellas recesiones de más de $5 \mathrm{~mm}$, mientras que en la cirugía mucogingival los resultados no se corresponden con la magnitud de la lesión inicial. Además el autor observa como se produce un importante aumento de encía insertada en el grupo de la RTG en comparación con el control a los seis meses, sin producirse deslizamiento de la inserción, por lo que el autor sugiere - en comunión con otros muchos autores - 
Tabla VI. Estudios clínicos comparativos CMG vs RTG.

\begin{tabular}{|c|c|c|c|c|c|c|}
\hline $\begin{array}{l}\text { Autor } \\
\text { Año } \\
\text { País }\end{array}$ & $\begin{array}{c}\text { Tratamiento } \\
\text { Periodo de estudio } \\
\text { (meses) }\end{array}$ & $\begin{array}{l}\text { Reducción de la } \\
\text { profundidad de la } \\
\text { RG. }\end{array}$ & $\begin{array}{l}\text { Reducción de la } \\
\text { profundidad de } \\
\text { Sondaje. }\end{array}$ & $\begin{array}{l}\text { Ganancia de } \\
\text { inserción. }\end{array}$ & $\begin{array}{c}\text { Aumento de la } \\
\text { encía queratinizada. }\end{array}$ & OBSERVACIONES \\
\hline $\begin{array}{l}\text { Pini Prato } \\
1992 \\
\text { Italia }\end{array}$ & $\begin{array}{c}\text { IGL + CRC } \\
\text { RTG (e-PTFE) } \\
18\end{array}$ & $\begin{array}{l}-3.62 \\
-4.12\end{array}$ & $\begin{array}{l}+0.06 \\
-1.00\end{array}$ & $\begin{array}{l}+3.56 \\
+5.12\end{array}$ & $\begin{array}{l}+5.32 \\
+0.56\end{array}$ & $\begin{array}{l}\text { No diferencia significativa, } \\
\text { salvo en el aumento de E.Q } \\
\text { para la CMG. }\end{array}$ \\
\hline $\begin{array}{l}\text { Pini Prato } \\
1996 \\
\text { Italia }\end{array}$ & $\begin{array}{c}I G L+C R C \\
\text { RTG (e-PTFE) } \\
48 \\
\end{array}$ & $\begin{array}{l}-3.84 \\
-4.24\end{array}$ & $\begin{array}{l}-0.06 \\
-0.80\end{array}$ & $\begin{array}{l}+3.09 \\
+5.04\end{array}$ & $\begin{array}{l}+5.12 \\
+1.28\end{array}$ & $\begin{array}{l}\text { No diferencia significativa, } \\
\text { salvo en el aumento de E.Q } \\
\text { para la CMG. }\end{array}$ \\
\hline $\begin{array}{l}\text { Ricci } \\
1996 \\
\text { Italia }\end{array}$ & $\begin{array}{c}I G L+C R C \\
\text { RTG (e-PTFE) } \\
12\end{array}$ & $\begin{array}{l}\text { ND } \\
\text { ND }\end{array}$ & $\begin{array}{l}\text { ND } \\
\text { ND }\end{array}$ & $\begin{array}{l}+3.05 \\
+5.55\end{array}$ & $\begin{array}{l}+2.11 \\
+2.27\end{array}$ & $\begin{array}{l}\text { No diferencia significativa, } \\
\text { salvo en la ganancia de } \\
\text { inserción en RTG. }\end{array}$ \\
\hline $\begin{array}{l}\text { Harris } \\
1997 \\
\text { USA }\end{array}$ & $\begin{array}{c}\text { DP (espesor parcial) } \\
\text { RTG (e-PTFE) } \\
\text { ND }\end{array}$ & $\begin{array}{l}-3.6 \\
-2.5\end{array}$ & $\begin{array}{l}-0.4 \\
-0.3\end{array}$ & $\begin{array}{l}\text { ND } \\
\text { ND }\end{array}$ & $\begin{array}{l}+3.1 \\
-0.4\end{array}$ & $\begin{array}{l}\text { No diferencia significativa, } \\
\text { salvo para defectos < de } 5 \\
\mathrm{~mm} \text {. que es mejor CMG. }\end{array}$ \\
\hline $\begin{array}{l}\text { Trombelli } \\
1997 \\
\text { Italia }\end{array}$ & $\begin{array}{c}\text { CRC } \\
\text { RTG (e-PTFE) } \\
18\end{array}$ & $\begin{array}{l}-2.4 \\
-3.7\end{array}$ & $\begin{array}{l}\text { ND } \\
\text { ND }\end{array}$ & $\begin{array}{l}+2.9 \\
+2.6\end{array}$ & $\begin{array}{l}-0.5 \\
+1.1\end{array}$ & No diferencia significativa. \\
\hline $\begin{array}{l}\text { Zuchelli } \\
1998 \\
\text { Italia }\end{array}$ & $\begin{array}{c}\text { ITC }+ \text { CRC } \\
\text { RTG (reab. y no reab.) } \\
12\end{array}$ & $\begin{array}{l}-5.3 \\
-4.9\end{array}$ & $\begin{array}{l}+0.47 \\
-0.11\end{array}$ & $\begin{array}{l}+4.7 \\
+4.9\end{array}$ & $\begin{array}{l}+3.1 \\
+0.7\end{array}$ & $\begin{array}{l}\text { Mejor CMG que no reabs. } \\
C M G \text { > ganancia de } E Q \text {. }\end{array}$ \\
\hline $\begin{array}{l}\text { Jepsen } \\
1998 \\
\text { Alemania }\end{array}$ & $\begin{array}{c}I G L+C R C \\
\text { RTG (e-PTFE-Ti) } \\
12\end{array}$ & $\begin{array}{l}-3.1 \\
-3.1\end{array}$ & $\begin{array}{l}+0.1 \\
+0.1\end{array}$ & $\begin{array}{l}+3.1 \\
+3.0\end{array}$ & $\begin{array}{l}+2.5 \\
+1.5\end{array}$ & No diferencia significativa. \\
\hline $\begin{array}{l}\text { Trombelli } \\
1998 \\
\text { Italia }\end{array}$ & $\begin{array}{l}\text { ITC }+ \text { CRC } \\
\text { RTG (reab.) } \\
6\end{array}$ & $\begin{array}{l}-2.5 \\
-1.6\end{array}$ & $\begin{array}{l}+0.2 \\
-0.1\end{array}$ & $\begin{array}{l}+2.3 \\
+1.7\end{array}$ & $\begin{array}{l}+1.8 \\
+0.8\end{array}$ & Mejor CMG. \\
\hline $\begin{array}{l}\text { Harris } \\
1998 \\
\text { USA }\end{array}$ & $\begin{array}{l}\text { ITC }+ \text { CRC } \\
\text { RTG (reab.) } \\
6\end{array}$ & $\begin{array}{l}-3.4 \\
-3.3\end{array}$ & $\begin{array}{l}-1.5 \\
-1.5\end{array}$ & $\begin{array}{l}\text { ND } \\
\text { ND }\end{array}$ & $\begin{array}{l}+2.1 \\
+0.1\end{array}$ & $\begin{array}{l}\text { No diferencia significativa } \\
\text { salvo en el aumento de EQ. } \\
\text { para la CMG. }\end{array}$ \\
\hline $\begin{array}{l}\text { Aranda } \\
1997 \\
\text { España }\end{array}$ & $\begin{array}{c}\text { ITC }+ \text { CRC } \\
\text { RTG (e-PTFE) } \\
12\end{array}$ & $\begin{array}{l}-2.8 \\
-3\end{array}$ & $\begin{array}{l}\text { ND } \\
\text { ND }\end{array}$ & $\begin{array}{l}\text { ND } \\
\text { ND }\end{array}$ & $\begin{array}{l}\text { ND } \\
\text { ND }\end{array}$ & No diferencia significativa. \\
\hline
\end{tabular}

ITC: inj. Tej. Conectivo. CRC: colg. Rep. Coronal. IGL: inj. Ging. Libre. DP: colg. Doble papila. RTG: regen. Tisular guiada. ND: no datos

EQ: encía queratinizada.

1. Todos los valores promedio en $\mathrm{mm}$.

2. Los parámetros resultan de restar la medida postoperatoria menos la preoperatoria. 
que la posición de la unión mucogingival está determinada genéticamente.

Similares resultados obtienen Trombelli y cols. (107) cuando repiten este estudio y comparan la técnica de reposición coronal del colgajo con la RTG (con membranas de e-PTFE). En este caso trata a 18 pacientes, usando en la técnica de RTG además acondicionadores radiculares (fibrina-fibronectina y tetraciclina). Los resultados a los seis meses son, igual que en el caso anterior, ligeramente mejores en la RTG, si bien es sorprendente que en el procedimiento de CMG se produjo una reducción de la encía insertada, debida, según el autor, al trauma quirúrgico y posterior remodelado tisular.

Este mismo estudio es repetido por Harris (108) en 1997, cuando compara la RTG (con aplicación de tetraciclina y membranas de e-PTFE) con la técnica de doble papila de espesor parcial. Obtiene con ambas técnicas resultados similares (algo mejores con la técnica de cirugía mucogingival) sin diferencias estadísticamente significativas, excepto cuando nos encontramos con defectos "estrechos" (menos de $5 \mathrm{~mm}$ de espesor de tejido en el área del defecto), en los que los resultados de la CMG son notablemente mejores.

En otro estudio realizado por Ricci y cols. (109) compara los procedimientos de RTG (membranas de ePTFE con colgajo de espesor total) y el injerto de tejido conectivo para el tratamiento de 18 casos de recesiones gingivales. No encuentra diferencias significativas en ambos procedimientos, aunque los parámetros clínicos son algo mejores en el caso de la RTG, siendo únicamente destacable la diferencia a favor de la RTG en lo referente a ganancia de inserción (5,5 vs. 3,05 mm).

Un estudio realizado por Zuchelli y cols. (110) compara los resultados de al RTG (con membranas reabsorbibles y no rebsorbibles) y la cirugía mucogingival (técnica bilaminar) en el tratamiento de defectos periodontales de 54 pacientes. Obtiene mejores resultados con la CMG en lo que a recubrimiento radicular se refiere cuando se compara con los resultados del grupo de membranas no reabsorbibles, no siendo así cuando dicha comparación se realiza con las membranas reabsorbibles. No aprecian diferencias significativas entre los diferentes tipos de membranas.

Otro estudio de este mismo año lo realizan Jepsen y cols. (111) en el que comparan los resultados de la RTG (e-PTFE) con los injertos de tejido conectivo (técnica envolvente). En ambos casos acondiciona la superficie radicular con clorhidrato de tetraciclina, no encontrando diferencias significativas en la profundidad inicial de las lesiones en ambos grupos. En la reevaluación a los doce meses se encuentra una disminución media de la recesión de 3,6 mm. para ambas técnicas $(87,1$ y $86,9 \%$ respectivamente),y una ganancia de encía queratinizada de $1,5 \mathrm{~mm}$. en el grupo de la RTG y de 2,5 $\mathrm{mm}$. en el grupo de la cirugía mucogingival.

Entre los estudios españoles encontramos el de Aranda y cols. (1997) (115) quienes obtuvieron un recubrimiento del $83 \%$ con las membranas Guidor AB. y un $78.6 \%$ con el injerto de tejido conectivo, no apareciendo diferencias significativas entre ambas técnicas en ninguno de los parámetros medidos.

Harris y cols. (1998) (112) comparó la eficacia del injerto de tejido conectivo y la RTG mediante membranas reabsorbibles en el tratamiento de 37 recesiones gingivales en 24 pacientes. La membrana estaba fabricada en ácido poliláctico suavizada con éster de ácido cítrico para mejorar su manejabilidad, mientras que la técnica de cirugía mucogingival consistía en un injerto de tejido conectivo palatino recubierto con un colgajo pediculado reposicionado coronalmente sin incisiones verticales (técnica "sobre"). Los resultados demostraron que no existían diferencias significativas $(92.3 \%$ y $95 \%$ de recubrimiento radicular respectivamente), excepto en el incremento de encía queratinizada, donde el ITC fue superior.

Un estudio de carácter histológico e histométrico donde se compara la formación de nuevo hueso, cemento y tejido conectivo de inserción con el ITC y la RTG es el realizado por Weng y cols. (1998) (113) en perros beagle. En él, se observa que no existen diferencias significativas en los parámetros anteriores salvo en la formación de nuevo hueso que fue superior en el grupo de RTG.

Para acabar, citaremos un estudio de Trombelli y cols. (114) de dicho año en el que compara la eficacia del ITC y la RTG en el tratamiento de recesiones gingivales. Trata a 12 pacientes con la técnica estándar y en la reevaluación a los 12 meses se observaron mejores resultados en la técnica de CMG (81\% de recubrimiento radicular frente a $48 \%$ obtenido con la RTG) en todos los parámetros observados.

\section{SUMIMARY}

Buccal recessions are one of the most common pathology of consult to the periodontology professional. They produce a characteristic symptomatology - by the root exposition - that may be treated functional and esthetically.

In the context of the periodontal surgery, many procedures has been developed. At present, it is though that the most predecible techniques to treat 
wide and deep recessions are free connective tissue graft and guided tissue regeneration procedures.

The objetive of this article is to review comparative studies between these techniques in order to finish which obtain better results.

\section{KEY WORDS}

Gingival recessions; root coverage; graft connective tissue;, guided tissue regeneration; mucogingival surgery.

\section{CONCLUSIONES}

A la luz de estos estudios podemos llegar a la conclusión de que ambos métodos parecen válidos para el tratamiento de recesiones anchas y profundas, si bien habría que esperar a posteriores estudios, ya que la creencia extendida de que la RTG es más predecible en defectos profundos (mayores de $5 \mathrm{~mm}$ ) queda en entredicho tras los últimos estudios mencionados, cuyos autores sugieren que los parámetros para decantarnos por un tipo de cirugía u otro quedarían determinados por las características anatómicas, el disconfor del paciente, el impacto económico, la higiene del paciente, etc.

De cualquier manera, en el tratamiento de recesiones pequeñas y estrechas estaría indicado un colgajo de reposición lateral o un colgajo de reposición coronal, siempre y cuando tengamos una adecuada área donante.Y para el tratamiento de recesiones anchas y profundas nos decantamos por un injerto gingival libre en el sector antero-inferior y para el resto tenemos el injerto de tejido conectivo y la regeneración tisular guiada como alternativas válidas en cuanto a cobertura radicular se refiere, mientras que con la cirugía mucogingival se puede conseguir un mejor resultado estético en el sector antero-superior y un aumento en la banda de encía queratinizada además de no incrementar el coste del tratamiento.

\section{BIBLIOGRAFÍA.}

1. Guinard EA, Caffesse RG. Treatment of localized gingival recessions I. Lateral sliding Flap. J. Periodontol., 1977; 48: 351-6.

2. Martinez-Sahuquillo JM, Bulón P. Etiopatogenia de las recesiones gingivales. Revisión bibliográfica. Av. en Periodoncia, 1995; 7:29-34.
3. Bouchard P, Etienne G, Ouhayoun J, Nilveus R. Subepithelial connective tissue grafts in the treatment of gingival recessions. A comparative study of procedures. J. Periodontal., 1994; 65:929-36.

4. Fombellida CF, Fernandez M, Pérez A, Martos F. Frecuencia de las recesiones gingivales. Revista de actualidad estomatológica Española, 1989, 14:23-7.

5. Martos Molino F, Fombellida F, Fernandez M. Tratamiento de las recesiones gingivales mediante injerto libre en encía libre de encía. Revista de actualidad estomatológica Española, 1988; Junio 23-9.

6. Hall WB. The current status of mucogingival problems and their therapy. J. Periodontol. 1981; 52: 569-75.

7. Raetzke PB. Covering localized areas of root exposure employing the "envelope" tecnique. J. Periodontol., 1985. 56: 397-403.

8. Carranza JR. Periodoncia clínica de Glickman. Ed. Interamerica Mc Graw-Hill. $7^{\text {a }}$ Ed.1990.

9. Rodriguez P, Castro Lara J, Ibero Sagastibelza I. Importancia clínica de la encía insertada en periodoncia, ortodoncia, odontología restauradora e implantología. Av. Periodoncia, 1998; 10:121-23.

10. Grupe J, Warren R. Repair of gingival defects by a sliding flap operation. J. Periodontol., 1956; 27: 290-5.

11. Walls $\mathrm{H}$, Kon S, Ruben PM. Colgajo de posición lateral. Clínicas Odontológicas de Norteamericana, 1988;2:276-98.

12. Smuckler H, Goldman HM. Laterally repositioned "stimuled" osteoperiosteal pedicle grafts int he treatment of denuded roots. a prelimay report. J. Periodontol., 1979; 50: 379-83.

13. Smuckler H. Laterally positioned mucoperiosteal pedicle grafts in the treatment of denuded roots. A clinical and statistical study. J. Periodontol., 1976; 47:590-5.

14. Matour AL. La recessión gingivale. Actualités OdontoStomatologiques, 1986; 154: 75-84.

15. Danan M, Deteienville E. La chirurgie mucogingivale. Actualités Odonto-Stomatologiques, 1985; 149: 129-51.

16. Meyer J, Huynh C, Angeraud R. Greffon gingival et lambeau positionné dans le traitement des dénudations radiculaires. Actualités Odonto-Stomatologiques, 1986; 154.

17. Colmenares MM, Tawse-Smith $A$. Tratamiento de una recesión gingival localizada de un caso. Universitas Odont., 1996; 15:11-9.

18. Patur B. The rotation flap for covering denuded root surfaces. A closed wound technique. J. Peridontol., 1977; 48:41-4.

19. Bahat $\mathrm{O}$, Handelsman M, Gordon J. The transpositioned flap in mucogingival surgery. Int. J. Periodontics Restorative Dent., 1990; 10:473-82.

20. Cohen DW, Ross SE. The double papilla repostioned flap in periodontal therapy. J. Periodontol., 1968; 39:65. 
21. Norberg O. Ar en utlakning utan vavnadsörlust otänkbar vid kirurgisk behandling av s.k. alvolarpyorrea? Svensk Tandläkar Tidskrift, 1926; 19:171.

22. Allen EP, Miller PD. Coronal postioning to existing gingiva. Short term result in the treatment of shallow marginal tissue recession. J. Periodontol., 1989; 60: 316-9.

23. Harris RJ, Harris AW. The coronally positioned pedicle graft with inlaid margins: A predictalbe method of obtaining root coverage of shallow defects. Int. J. Periodontics Restorative Dent., 1994; 14: 229-41.

24. Blanc, Pare-Dargent, Giovannoli: Traitement des recessions gingivales par lambeau positionne coronairement. J. de Parodontologie, 1991; 10: 329-34.

25. Bernimoulin JP, Lüchsen B, Mühlemann HR. Coronally repositioned periodontal flap. J. Clin. Periodontol., 1975; 2:1.

26. Maynard JG. Coronal postioning of a previously placed autogenous gingival graft. J. Periodontol., 1977; 48: 151.

27. Wennström. Annals of Periodontology 1996. AAP.

28. Tarnow DP. Semilunar coronally repositioned flap. J. Clin. Periodontol., 1986; 13: 182-5.

29. Björn H. Free transplantation of gingiva propria. Sven Tandlak. Tidskr., 1963; 22: 684.

30. Sullivan HC, Atkins JH. Free autogenous gingival grafts. 3. Utilization of grafts in the treatment of gingival recession. Periodontics, 1968; 6:152.

31. Sullivan HC, Atkins JH. Free autogenous gingival grafts. 1. Principles of succesful grafting. Periodontics, 1968; 6:121.

32. Miller PD. Root coverage using a free soft tissue autograft following citric acid application. I. Technique. Int J. Period. Restorative Dent., 1982; 2:65-70.

33. Miller PD. Root coverage using a free soft tissue autograft following citric acid application. III. Technique. Int J. Period. Restorative Dent., 1985; 2:15-37.

34. Miller PD. Root coverage with the free gingival graft. Factors associated with incomplete coverage. J. Periodontol, 1987; 58:674-81.

35. Holbrook I, Ochsenbein C. Complete coverage of the root surface with a one-stage gingival graft. Int. J. Period. Restorative Dent., 1983; 3: 9-27.

36. Corn H, Marks M. Gingival grafting for deep-wide recession. A status report. I. Rationale, case selection and root preparation. Compend. Cont. Educ. dent., 1983; 4:53.

37. Corn H, Marks M. Gingival grafting for deep-wide recession. A status report.II. Surgical problems. Compend. Cont. Educ. dent., 1983; 4:167.

38. Ibbott CG, Oles RD, Laverty WH. Effects of citric acid treatment of autogenous free graft coverage of localized recession. J. Periodontol., 1985; 56:662-5.
39. Bertrand PM, Dunlap RM. Coverage of deep, wide gingival clefts with free gingival autografts: root planing with and without citric acid demineralization. Int. J. Periodon. Restorative Dent., 1988; 8:65-77.

40. Charlene A, Czuszak GE, Tolson GE. Development of an Exostosis following a free gingival graft: A case report. J. Periodontol, 1990; 40:158-63.

41. Otero-Cagide FJ, Singer DL, Hoover JN. Exostosis associated with autogenous gingival grafts: a report of 9 cases. J. Periodontol., 1996; 67:611-6.

42. Langer B, Langer L. Subepithelial connective tissue graft technique for root coverage. J. Periodontol., 1985; 56:71520.

43. Perez A. Injerto submucoso libre de encía. Una nueva perspectiva. Boletín de información dental, 1982; 42:63-8.

44. Nelson PB. The subpedicle connective tissue graft; a bilaminar reconstructive procedure for the coverage of denuded root surfaces. J. Periodontol., 1987; 58:95-102.

45. Harris RJ. The connective tissue and partial thickness double pedicle graft. A predictable method of obtaining root coverage. J. Periodontol., 1992; 63: 477-86.

46. Harris RJ. The connective tissue and partial thickness double pedicle graft. The results of 100 consecutively treated defects. J. periodontol, 1994; 65:448-61.

47. Allen AL. Use of the supraperiosteal envelope in soft tissue grafting for root coverage. II. Clinical results. Int. J. Periodon. Rest. Dent., 1994; 14:303-15.

48. Tinti C, Parma-Benfenati S. The free rotated papilla autograft: a new bilaminar grafting procedure for the coverage of multiple shallow gingival recessions. J. Periodontol., 1996; 67:1016-24.

49. Karring T, Lang NP, Löe H. Role connective tissue in determining epithelial specifity. J. Dental Research, 1972; 51:1303-4.

50. Stambaugh RU, Gordon HP. Connective tissue influence on mucosal keratinization. J. Dent. Res. (Special Issue), 1972; 51: $14 \mathrm{t}$.

51. Guinard EA, Caffesse RG. Treatment of localized gingival recessions III. Comparison of results obtained with lateral sliding and coronally repositioned flaps. J. Periodontol., 1978; 49: 457-61.

52. Caffesse RG, Guinard EA. Treatment of localized gingival recessions. Part 4. Results after three years. J. Periodontol., 1980; 51:167.

53. Espinal MC, Caffesse RG. Lateral positioned pedicle sliding flap. Revised technique in the treatment of localized gingival recession. Int. J. Periodon. Rest. Dent., $1981 ; 43-51$.

54. Oles RD, Ibbot CG, Laverty WH. Effects of citric acid treatment on pedicle flap coverage of localized recession. J. Periodontol., 1985; 56:259-61. 
55. Borguetti $A$, Gardella JP. Thick gingival autograft for the coverage of gingival recession: a clinical evaluation. Int. J. Periodon. Rest. Dent., 1990; 10:217-29.

56. Wennström JL, Zucchelli G. Increased gingival dimensions-a significant factor for succesful out-come of root coverage procedures? A 2-year prospective clinical study. J. Clin. Periodontol., 1996; 23: 254-65.

57. Tolmie PN, Rubins RP, Buck SG, Lanz JC. The predictability of root coverage by way of free gingival autograft and citric acid applicatin: An evaluation by multiple clinicians. Int. J. Periodon. Rest. Dent., 1991; 4:261-71.

58. Michaelides PL, Wilson SG. An autogenous gingival graft technique. Int. J. Periodon. Rest. Dent., 1994; 14:113-25.

59. García-Calderón M, Gutiérrez JL, Compagni R. El injerto gingival libre como tratamiento de la recesión gingival en el maxilar inferior: evaluación a los 3 años. Av. en periodoncia, 1997; 9:35-43.

60. Borguetti $\AA$, Louise F. Controlled clinical evaluation of the subpedicle connective tissue graft for the coverage of gingival recession. J. Periodontol., 1994; 65: 1107-12.

61. Matter J. Free gingival graft and coronally repositioned flap. A 2-year follow-up report. J. Clin. Periodontol., 1976; 6:437-42.

62. Liu WJL, Solt CW.A surgical procedure for the treatment of localized gingival recession in conjunction with root surface citric acid conditioning. J. Periodontol., 1980; 51:505-9.

63. Tenenbaum H, Klewansky P, Roth JJ. Clinical evaluation of gingival recession treated by coronally repositioned flap technique. J. Periodontol., 1980; 51:686-90.

64. Mlinek A, Smuckler H, Buchner A. The use of free gingival grafts for the coverage of denuded roots. J. Peridontol., 1973; 44:248-54.

65. Zade RM, Hirani SH. A clinical study of localized gingival recession treated by lateral sliding flap. J. Periodontal., 1985; 57:19-26.

66. Oles RD, Ibbott CG, Laverty WH. Effect of root curettage and sodium hypochlorite treatment on pedicle flap coverage of localized recession. J. Can. Dent. Assoc., 1988; 54:515-7.

67. Kunjamma S, Varma BRR, NandaKumar KA. A comparative evaluation of coverage of denuded root surface by gingival autograft and lateral sliding flap operation. J. Indian Dent. Assoc., 1986; 58:527-34.

68. Romanos GE, Bernimoullin JP, Marggraf E. The double lateral briding flap for coverage of denuded root surface: Longitudinal study and clinical evaluation after 5 to 8 years. J. Periodontol., 1993; 64:683-88.

69. Matter J, Cimasoni G. Creeping attachment of free gingival grafts. A five-year follow-up study. J. Periodontol., 1980; 51:681-5.

70. Levine RA. Covering denuded maxillary root surfaces with the subepithelial connective tissue graft. Compen. Cont. Educ. Dent., 1991; 12:568-77.

71. Jahnke PV, Sandifer JB, Gher ME, Gray JL, Richardson AC. Thick free gingival and connective tissue autografts for root coverage. J. Peridontol., 1993; 64:315-22.

72. Bascones A. Diagnostico y tratamiento de la enfermedad periodontal. Ed. Avances. 1992.

73. Gottlow J, et al. New attachment formation as a result of controlled tissue regeneration. J. Clin. Periodontol. 1984; 11:494-503.

74. Caffesse RG, Quiñones CR. Guided tissue regeneration: Biologic rationale, surgical technique, and clinical result. Compend. contin. educ. dent. 1992; (13) 3:166-77.

75. Sanchez Garcés MA., Urilbarri Echevarria A., Iraculis Sotores X. Regeneración ósea. Técnicas y materiales. Revisión de la literatura publicada en los años 1993 y 1994. Arch. Odontoestomatol. 1996; (12) 8:471-79.

76. Monlleó PJ. Regeneración tisular guiada en la terapia periodontal: Revisión bibliográfica, técnica e indicaciones. Rev. Act. Odontoestomat. esp. 1995; (55) 3:45-54.

77. Echeverri M, Duarte S., Valderrama MP., Pérez JJ. Regeneración tisular guiada en periodoncia. Una revisión. Univers. Odont. 1995; (15) 28: 27-39.

78. Remolina Ruiz A, Aguirre Zorzano LA., Bayona Iturrarte J., Fernandez R. Regeneración tisular guiada. Periodoncia 1996; (6) 1:25-40.

79. Dowell P., Moran J., Quteish D. Guided tissue regeneration. Brit. Dent. J. 1991; 7:125-7.

80. Tinti C., Vincenzi G., Cortellini P., Pini Patro G., Clauser C. Guided tissue regeneration in the treatment of human facial recession. A 12 case report. J. Periodontol. 1992; (63) 6:554-60.

81. Melcher AH. On the repair of periodontal tissuts. J. Periodontol. 1976; 47:256-60.

82. Nyman S., Karring T., Lindhe J. Healing following implantation of periodontitis affected roots into gingival connective tissue. J. Clin. Periodontol. 1980; 7:394-401.

83. Nyman S. Gottlow J., Karring T. The regenerative potential of the periodontal ligament. An experimental study in the monkey. J. Clin. Periodontol. 1982; 9: 257-65.

84. Nyman S, Lindhe J, Karring T. New attachment following surgical treatment of human periodontal disease. J Clin Periodontol. 1982; 9: 290-96.

85. Gottlow J, Nyman S, Lindhe J, Karring T. New attachment formation in the human periodontium by guidded tissue regeneration. Case reports. J Clin Periodontol. 1986; (13) 6:604-16.

86. Buser D., Brägger U., Lang NP., Nyman S. Regeneración y aumento de reborde maxilar utilizando la técnica de regeneración tisular guiada. Periodoncia 1992; (2) 1:52-64. 
87. Cortellini P. Guided tissue regeneration procedure using a fibrin-fibronectine system in surgically induced recessions in dogs. Int. J. Periodontics. Restorative. Dent. 1991; 11: 151-63.

88. Pini Prato G., Tinti C., Cortellini P., Magnani C., Clauser C. Periodontal Regenerative Theraphy with coverage of previously restore root surfaces: cases reports. Int. J. Periodontics Restorative Dent. 1992; (12) 6: 451-61.

89. Pini Prato G., Tinti C., Vincenzi G., Magnani C. Guided Tissue Regeneration versus mucogingival surgery in the treatment of human buccal recession. J. Peridontol. 1992; (63) 11:919-27.

90. Torosian J., Rosenberg ES. The use of guided tissue regeneration in enhancing anterior esthetics: A case report. Compend. Contin. Educ. Dent. 1992; (13) 4: 302-10.

91. Cortellini P., Clauser C., Pini Prato GP. Histologic assessment of attachment following the treatment of a human buccal recession by means of a guided tissue regeneration procedure. J. Periodontol. 1993; (64) 5:387-91.

92. Tinti C., Vicenzi G., Coccheto R. Guided tissue regeneration in mucogingival surgery. J. Periodontol. 1993; (64) 11:1184-91.

93. Pini Prato G., Clauser C., Cortellini P. Guided tissue regeneration and a free gingival graft for the management of buccal recession: $A$ case report. Int. J. Periodontics Restorative Dent. 1993; (13) 6: 487-93.

94. Tinti C, Vincenzi G. e-PTFE titanium reinforced membranes for regeneration of mucogingival recession defects. A case report. J Periodontol. 1994; 65: 1088-94.

95. Trombelli L., Schincaglia G., Checchi L., Calura G. Combined guided tissue regeneration, root conditioning and fibrin-fibronectin system application in the treatment of gingival recession. A 15-cases report. J. Periodontol. 1994; (65) 8:796-803.

96. Santos Alemany A. Tratamiento de la recesión gingival bucal mediante la técnica quirúrgica. Periodoncia 1995; (5) 2: 100-8.

97. Trombelli B., Schincaglia GP., Scapoli C., Calura S. Healing response of human buccal gingival recession treated with expanded- PTFE membranes. A retrospective report. J. Periodontol. 1995; (66) 1: 14-22.

98. Trombelli L., Calura G. Recubrimiento total de superficies denudadas a través de la aplicación de una membrana de PTFE expandido en combinación con un tratamiento local de tetraciclinas y el uso de un pegamento con fibrinafibronectina. Quintessenz. 1995; (8) 10:664-69.

99. Pini Prato G., Clauser C., Magnani C., Cortellini P. Resorbable membranes in the treatment of human buccal recession: A 9-cases report. Int. J. Periodontics Restorative Dent. 1995; (15) 3: 258-67.

100. Roccuzzo M., Buser D. Treatment of buccal gingival recession with e-PTFE membranes and miniscrews: surgical procedures and results of 12 cases. Int. J.
Periodontics Restorative Dent. 1996; (16) 4:357-65.

101. Ito K., Murai S. Adjacent gingival recessions treated with e-PTFE membranes: A report of 2 cases. J. Periodontol. 1996; (67) 4: 443-53.

102. De Sanctis M., Zucchelli G. Guided tissue regeneration with a resorbable barrier membrane (Vicryl) for the management of buccal recession: A case report. Int. J. Periodontics Restorative Dent. 1996; (16) 5:435-41.

103. Waterman CA. Guided tissue regeneration using a bioabsorbable membrane in the treatment of human buccal recession. A re-entry study. J. periodontol. 1997; (68) 10:982-89.

104. Shieh A., Wang H., O'neal R., Glickman GN., Macneil $\mathrm{RL}$. Development and clinical evaluation of a root coverage procedure using a collagen barrier membrane J. Periodontol. 1997; (68) 8: 770-8.

105. Trombelli L., Schincaglia GP., Zangari F., Griselli A. Effects of tetraciclines HCL conditioning and fibrinfibronectin system application in the treatment of buccal gingival recession with guided tissue regeneration. J. Periodontol. 1995; (66) 5:313-20.

106. Pini Prato G., Clauser C., Cortellini P., Tinti C. Guided tissue Regeneration versus Mucogingival surgery in the treatment of human buccal recession. A 4- years follow- up study. J. Periodontol. 1996. (67) 11: 1216-23.

107. Trombelli L., Tatakis D., Scabbia A., Zimmerman GJ. Comparison of mucogingival changes following treatment with coronally positioned flap and guided tissue regeneration procedures. Int. J. Periodontics Restorative Dent. 1996; (17) 5: 448-55.

108. Harris RJ. A comparative study of root coverage obtained with guided tissue regeneration utilizing a bioabsorbable membrane versus the connective tissue with partial-thickness double pedicle graft. J. Periodontol. 1997 ; (68) $8: 779-90$.

109. Ricci G., Silvestri M., Tinti C., Rasperini G., A clinical/statistical comparison between the subpedicle connective tissue graft method and the guided tissue regeneration technique in the root coverage. Int. J. Periodontics Restorative Dent. 1996; (16) 6:539-45.

110. Zucchelli G., Clauser M., De Sanctis M., Calandriello M. Mucogingival versus guided tissue regeneration procedures in the treatment of deep recession type defects. J. Periodontol. 1998; (69) 2: 138-435.

111. Jepsen K, Heinz B, Halben JH, Jepsen S. Treatment of gingival recession with titanium reinforced barrier membranes versus connective tissue grafts. J Periodontol. 1998; (3) 69: 383-91.

112. Harris RJ. A comparison of two root coverage techniques: guided tissue regeneration with bioabsorbable matrix style membrane versus a connective tissue graft combined with a coronally positioned pedicle graft without vertical incisions. Results of a series of consecutive cases. J. Peridontol. 1998; (12) 69: 1426-34. 
113. Weng D, Hürzeler MB, Quiñones CR. Healing patterns in recession defects with ePTFE membranes and with free connective tissue grafts. A histologic and histometric study in the beagle dog. J Clin Periodontol. 1998; 25: $238-45$.

114. Trombelli L., Scabbia A., Tatakis DN., Calura G. Subpedicle connective tissue graft versus guided tissue regeneration with bioabsorbable in the treatment of human gingival recession defects. J. Periodontol. 1998; (11) 69:1271-77.
115. Aranda JJ., Lazaro PJ., Sanz M. Surgical treatment of wide an isolated gingival recessions. Guided tissue Regeneration (GTR) versus supraperiostical "envelope" technique. J. Clin. Periodontol., 1997; (10):872 (Abstrac of clinical, research and poster presentation of Europerio 2). 
